\title{
Further exploring the rationality of evidence informed practice: A semiotic analysis of the perspectives of a school federation
}

\section{Chris Brown}

\begin{abstract}
This paper examines the rationality of evidence-informed practice (EIP) It presents pre intervention empirical evidence to provide an indication of what might facilitate more effective research-to-practice connections. The analysis is framed by two theoretical perspectives: 1) optimal rationality, and 2) semiotics. These perspectives are used to explore what evidence-use means to teachers, why they do or do not seek to use evidence to improve teaching and how these positions might be shifted in favour of more evidence informed approaches. Interviews were conducted with 15 teachers (the entirety of the teaching staff). Findings suggest that teachers need practical experience of EIP to engage with it, but they also need encouragement and support in relation to networked collaboration if EIP is to move out of individual classrooms and become a cultural norm at the level of the school/federation.
\end{abstract}

\section{Introduction: using evidence in education}

The idea that 'evidence' can be used to improve teaching practices and pupil outcomes, ultimately leading to improvements at a system level, is currently fashionable in education, both nationally and internationally (HammersleyFletcher and Lewin, 2015). This focus is not without merit: for example it is observed by Supovitz (2015) that a common characteristic of some of the 
most highly performing school systems is that they facilitate the collaborative examination of research evidence in order to identify likely problem areas (in terms of teaching and learning) as well as potential solutions to these problems. Likewise, analysis by Mincu (2014) suggests that where research is used as part of high quality initial teacher education and ongoing professional development, that this makes a positive difference in terms of teacher, school and system performance.

Yet, at the same time, there exists a recognised failure, on an international scale, of evidence to make a widespread and sustained impact on the practices of educators (Bryk et al., 2011; Nelson et al., 2015); and, despite considerable activity, the development of system-wide processes to meaningfully connect research and practice across the piece remain underdeveloped (Gough et al., 2011). In part this research and practice 'gap' may be a reflection of the critique often levelled at the perceived use value of educational research for practitioners. For instance, in relation to perceived deficits in the clarity, timeliness, relevance and usability of research; of the lack of ready amenability of research to action/transfer; or in terms of its lack of applicability and sophistication (e.g. how well the research-based information aligns with classroom needs and local contexts) (Dagenais et al., 2008; Nelson and O'Beirne, 2014). In addition, many schools have found it difficult to become 'research-engaged'; with teachers often lacking the skills, resource or the motivation to use evidence (e.g. Cooper et al., 2009). 
Simultaneously however, it is recognised that there has been little research undertaken to provide a research base on evidence-use that might address this critique (Nelson and O'Beirne, 2014; Cain, 2015). In other words, perhaps in an ironic twist, the evidence-use movement is itself not yet able to draw on a comprehensive and rigorous evidence base to either justify its beliefs or to put forward proven suggestions for how teachers might employ evidence effectively (Cain, 2015). While this is now being addressed through initiatives, such as the Education Endowment Foundation's $£ 1.4 \mathrm{~m}$ investment in projects focusing on approaches to increasing the use of research in schools, it will take a number of years before the evaluations of these projects emerge; and longer still before any meta-analysis or synthesis of them might be undertaken and used to provide an overarching frame outlining effective and less effective ways to connect research and practice. In the meantime this leaves simply the promising but nascent indication of benefit that already exists (detailed above) along with the strong moral and efficiency arguments for continuing to seek to better connections between evidence and practice (e.g. Shavelson and Towne, 2002; Oxman et al., 2009).

This paper is situated within this context: it is grounded in the belief that approaches for connecting research and practice should be pursued, and presents pre intervention empirical evidence to provide an indication of what might facilitate more effective research and practice connections. The paper is also grounded in [citation removed for peer review]'s argument that, because the concept of evidence use is intrinsically bound to trends and phenomenon that affect our day to day lives, research on evidence use should be explicitly 
situated within current sociological theory. Correspondingly the empirical analysis that is presented is framed by two pertinent theoretical and methodological perspectives: 1) the concept of optimal rationality; and 2) the analytical approach of semiotics. These are used to explore what evidence use means to teachers, why they do or do not seek to use evidence to improve teaching and how these positions might be shifted in favour of evidence informed practice (EIP). It begins, however, by providing a definition for EIP as well as outlining the factors that affect its realisation.

\section{Defining evidence-informed practice}

The proposed relationship between evidence and practice can be found expressed in various ways; in themselves these broadly represent an evolution from the idea that teaching can be based on evidence, to the realisation that it is perhaps more realistic, relevant and effective to consider situations where teaching practice is informed by evidence: with the coining of the phrase evidence-informed practice (EIP) representing a change of emphasis that favours teachers employing a myriad of evidence types, including their tacit expertise, in order to make effective decisions in specific contexts (Nelson and O'Beirne, 2014; Hammersley-Fletcher and Lewin, 2015). This shift is reflected in the definition of EIP provided by England's (as was) National College for Teaching and Leadership who suggest EIP comprises a situation in which:

All teaching practice reflects both individual teaching expertise and the best and most up-to-date external evidence from systematic research 
(from Hammersley-Fletcher and Lewin, 2015: 9).

More specifically in relation to this definition, and in keeping with [citation removed for peer review] for definitional purposes this paper considers 'external' research as that which has been peer reviewed and published by academic researchers. Systematic research, meanwhile, is considered to comprise meta-analyses or syntheses such as those produced by Hattie (e.g. 2011). As with previous work and in keeping with these definitions, the terms 'research' and 'evidence' are used interchangeably within this paper and treated as synonymous throughout.

\section{Optimal Rationality}

It is also important to recognize that the pursuit of EIP is (in theory at least) grounded in notions of rationality ([citation removed for peer review]). The concept of Optimal Rationality (OR) was originally presented by [citation removed for peer review] to explain why educators may or may not employ research to inform their practice, despite the apparent benefits of doing so. As [citation removed for peer review] explains, OR provides a conception of rationality grounded in philosophy rather than economics, and that originates from a rejection of the Kantian universal moral imperative, combined with a repositioning of Aristotelian reasoning. More specifically, optimal rationality suggests that any analysis of what rationality is or comprises should focus two things: 1) what individuals actually do in order to achieve goals (their practical rational acts); and 2) people's understanding of the wider context for their actions (the cultural rational environment). There are three key aspects of OR 
that spotlight its relevance to EIP: first is that OR examines people's behaviour, both in terms of the timescales involved and with regards to who might be affected by particular actions. In other words, OR argues that researchers should consider rationality according to both when the implications of actions are likely to materialise and in terms of who they might effect. According to OR, the effects of actions are therefore likely to range, on one hand, from being fully universal to being fully individual, and on another from focusing on the short-term to centering on the long term. This is important because factors such as time pressure (or even the pressures of accountability), are likely to encourage short term 'wins'; meaning teachers' attention can often be focused towards particularly narrow rational acts (in terms of the class they are teaching here and now) and away from pursuing actions that could bear fruit and be of benefit to many for much longer in the future (in many ways this is akin to a consumption vs. investment analogy).

Second, and building on the first point above, OR argues that, whether in terms of when or who, in all cases behaviour is rational when it is concerned with maximizing 'wellbeing'. This does not mean however the type of welfare maximization postulated by models of rationality such as Rational Choice Theory (e.g. Green, 2002; Sen, 1990; Tan, 2014); instead OR suggests that practical rational acts represent those things that individuals 'know' are 'needed' at a given point in time. As [citation removed for peer review] states:

[quotation removed for peer review] 
Third, relates to the need to incorporate concepts designed to explain society's role in instilling values or norms into individuals, in order to provide a wider context within which actions play out and are contextualized. Within OR, these serve to guide the cultural rational position; i.e. these represent the things that producers, society, groups within society, or perhaps even more localized cultures such as schools or government departments, deem as vital to the wider wellbeing and so seek to embed and enforce. Again points two and three serve to highlight a potential tension between teachers being incentivized to achieve short term benefits and their recognition (if any) of the need to pursue other approaches favoured by educational policy-makers, (such as EIP) which may not be instantly realised.

Within OR, consideration is also required of how the two modes of cultural and practical rationality interrelate or affect behaviour. It is clear, for example, that an individual may consider and act in accordance with either one or both at a given point in time. It is not unreasonable (and therefore it is not irrational), for instance, that individuals will seek to pursue an entirely practical path (which will likely amount to individuals focusing on the welfare of the short term self: for example knee jerk responses to the demands of accountability). An approach that is not only rational but also optimal however (and which gives OR its name) is that, on aggregate, there is balance or alignment between the cultural and the practical. This is because at a point of balance, when an individual or sub-group pursues their desires, they do so in ways congruent with approaches that also benefit either society or themselves in the long-term. 


\section{EIP as rational act}

It is evident that there now exists a general cultural rational position favouring EIP: for instance the direction of travel of recent educational policy in England and elsewhere focuses strongly on promoting/requiring teachers to better engage with evidence (Stoll, 2015). It is also apparent from recent announcements by organizations such as the Education Endowment Foundation (EEF), who recently launched a $£ 1.4 \mathrm{~m}$ fund to improve the use of research in schools (EEF 2014). In addition, this position can be associated with the rise of bottom up/teacher led initiatives, such as the emerging network of 'Teachmeets'i and 'ResearchED'ii conferences (Galdin O'Shea, 2015) designed to help teachers connect more effectively with research. Finally the cultural rational position is also reflected in a recent content analysis of the websites and school policy documents of 100 Teaching Schools (Caldwell et al., 2015), which shows how the majority claim both to be promoting evidence-use as well as having mechanisms in place to ensure the engagement by teachers with evidence.

\section{Exploring the rationality of evidence use}

[citation removed for peer review] previously used OR as a theoretical framework as part of a study of 696 primary teachers in 79 schools in England. Specifically, exploring the question: 'if EIP is rational behaviour, why aren't all teachers engaged in it?', [citation removed for peer review]'s study examined whether the beliefs and perspectives of teachers in relation to EIP, aligned with their evidence-use behaviours. [citation removed for peer 
review]s analysis revealed that, amongst the teachers they surveyed, there was often a significant discrepancy between their beliefs (their support for cultural rational position of EIP as a basis for improving teaching) and their actual practices in relation to evidence use (i.e. whether respondents themselves engage in the practical rational act of using evidence to improve their teaching). But [citation removed for peer review] also found that this discrepancy did not materialize, as they had expected, from practitioners believing they should seek to be evidence-informed whilst finding it difficult to engage in EIP; rather it occurred because EIP often did not appear to hold as a school level cultural norm - i.e. in many of the 79 schools comprising the sample, there appeared to be little acceptance of the cultural rational position that EIP should represent a guiding school-level culture or decision-making.

Correspondingly, evidence-use, when it did occur, seemed to materialize primarily as individual practical rational acts undertaken by some teachers within their classrooms. [citation removed for peer review] concluded by suggesting that, future research in this area would benefit from an in-depth and contextually situated understanding of the issues facing teachers and schools in relation to using and engaging with evidence. For instance, deeper qualitative investigation would provide richer understanding in terms of what is actually driving the type of discrepancy detailed above and so provide more insight into how disconnections between practical and cultural rational positions might be resolved.

\section{A semiotic perspective}


It is argued (e.g. see [citation removed for peer review], 2013, 2014, 2017; also see Ball, 2008, 2012; Fairclough, 1995; Gibbons et al., 1994) that for both educational policy-makers and practitioners, research evidence has many of the qualities associated with a 'consumer' object: for instance consuming research evidence comes at a cost (of access, the cost of commissioning research, the cost of training required to understand it), research-evidence is also judged by potential users in relation to its functionality and quality, as well as in relation to competing products, sources of information or approaches for school improvement (ibid). The field of semiotics is concerned with perception and meanings: specifically, the interpretations that individuals, groups and even societies associate with words, images, objects or other 'things' that can be used to signify [indicate] meaning (Peirce, 1960; Eco, 1967, 1979). Baudrillard (1968) argues that where signifiers, such as research evidence, represent objects which can be 'consumed', these objects can be considered as possessing a number of semiotic values, including: 1) the object's 'use' value - which corresponds to the perceived utility that can be derived from the object; 2) the object's exchange value - which represents perspectives on the price the object can command; and 3) the object's value as a 'sign' - in other words, the meaning the object holds for groups or individuals.

Given the posited nature of research as consumer object [citation removed for peer review], a semiotic approach, incorporating Baudrillard's analysis, can be used to examine the signification associated with teachers' evidence consumption patterns. Specifically, a semiotic analysis can be used to explore 
why teachers may be willing to adopt the practical rational position of consuming research for its use value (i.e. to inform their practice), but why they may not consume evidence in a way that positions themselves or their school as signifying the cultural rational position of being evidence-informed. What's more, a semiotic methodology can also used to explore whether and why it is that certain approaches to promoting/encouraging research-use can serve to shift the web of meaning towards favouring the cultural rational position of EIP.

\section{Chestnut Learning Federation: seeking to become research engaged}

The Chestnut CE Learning Federation is a family of three small Church Infant Schools based in the Hampshire villages of Rosebush, All Saints and Southampton Common, who all work closely together under the leadership of the Federation Headteacher and Governing Body. The vision of the three schools is to ensure children grow up to lead safe, happy, healthy and successful lives by providing the highest standard of education and the opportunity for each child to attain their own, full potential. One of the Federation's improvement plan objectives is for it to become an evidenceinformed Federation where schools collaborate to rigorously evaluate the quality of the education they offer, understand what they need to do to improve, to take appropriate evidence-informed action and to evaluate the impact of their actions, enabling them to achieve together.

To meet this objective, the executive headteacher has developed a model of professional learning in which (as from the 2016/17 school year) four of the 
statutory staff professional development (INSET) days allocated to schools in England will be dedicated solely to evidence-informed professional development. Using a cycle of enquiry approach, the aim of the model is to enable teachers to engage collaboratively with research, to develop new practices, to trial these practices, to measure their impact and then roll out the most successful within and across schools in the Federation.

\section{Methodology}

This paper explores the context for the roll out of the evidence-informed school improvement approach developed by Chestnut Learning Federation, and what is required from this approach if it is to move the Federation towards the optimal rational position of EIP. It does so via a semiotic analysis of the perspectives of Chestnut's staff in relation to cultural and practical rational aspects of EIP. The research questions addressed by the paper are, in terms of the Chestnut Learning Federation model of evidence-informed improvement:

1. What are the pre intervention perceptions of staff in relation to the cultural rational and practical rational positions corresponding to EIP?

2. What is the semiotic signification initially associated with EIP within the Chestnut Learning Federation?

3. What might be required to shift the current semiotic signification associated with evidence-use within Chestnut Learning Federation towards that of the optimal rational position of EIP? 
To address these questions a qualitative methodology was employed. For research question 1) in-depth semi-structured interviews were used to collect pre intervention data on the cultural rational and practical rational positions Chestnut's staff associated with EIP. Data was collected using measures based on those developed as part of [citation removed for peer review]s study into research-use amongst 696 primary schools teachers in England; these measures are set out in table 1 below. The qualitative versions of these questions, however, invited exploration rather that sought to replicate [citation removed for peer review]s measure of agreement using Likert scales.

Table 1: Pre intervention survey questions on research-use

1) Information from research plays an important role in informing my teaching practice

2) I have found information from research-useful in applying new approaches in the classroom

3) I do not support implementing a school-wide change without research to support it

4) I do not support implementing a Federation-wide change without research to support it

5) In the last year, I have discussed relevant research findings with colleagues in my school

6) In the last year, I have discussed relevant research findings with colleagues in the Federation 
For research questions 2) and 3) a semiotic framework was developed to enable an examination of the meaning of evidence-informed practice: what it signifies and why to teaching staff, as well as where EIP sits within the wider gamut of signification that operates within the Chestnut Learning Federation. The framework was also used to identify what other factors are seen as more or less important than EIP and to provide a baseline set of information from which it might be possible to assess whether the meaning and the importance attributed to EIP can be altered. To operationalise the framework pre intervention interview data was collected using semi-structured in-depth interviews. Questions were developed in relation to the three Baudrillardian semiotic domains of consumption outlined above: i.e. in relation to the use value (sample question: "In terms of ways of improving practice, how effective is using evidence? Why?"), exchange value (sample question: "In terms of ways of improving practice, how 'costly' is using evidence? Prompt in terms of time, money, training etc."), and signifying values associated with evidence use (sample question: "When I say research informed teaching, what image does that convey to you?"). Questions were also asked in relation to the background, values and beliefs of respondents.

\section{Analysis and findings}

A total 15 teachers were interviewed in September 2016 (representing the whole of the federation's teaching staff). The characteristics of the respondents are set out in table 2, below. Interviews were recorded and these recordings transcribed. Data from the recordings were analysed thematically, 
first to ascertain the practical and cultural rational perspectives of participants and then to ascertain their perspectives in relation to each of the Baudrillardian domains outlined earlier (i.e. in terms of the use, exchange and the signifying values participants associated with evidence use).

Beginning with the analysis of the practical and cultural rational perspective; data indicates that there exists a much wider variety of practical and cultural rational positions relating to research-use than those originally identified by [citation removed for peer review]. Broadly these practical and cultural rational positions can be allocated according to a combination of whether respondents believed they used research to improve their practice (or not) AND/OR whether respondents were in favour of a school or federation level commitment to using research to improve practice (or not). This is illustrated in Figure 1 below, which places each respondent into one of four quadrants; with participants allocated according to whether they were in broad agreement or disagreement with the interview questions relating to both practical and cultural rational positions (here the '+' sign indicates positive association or agreement, the '-' sign indicating a negative association or disagreement).

Table 2: Characteristics of the interview respondents

\begin{tabular}{|l|l|}
\hline Gender & 12 Female (92\%), 1 Male (8\%) \\
\hline Average time in post & 9 years \\
\hline Average age bracket & $46-50$ \\
\hline Number with post graduate qualifications & $5(38 \%)$ \\
\hline
\end{tabular}


Figure 1: Allocation of respondents according to practical and cultural rational beliefs

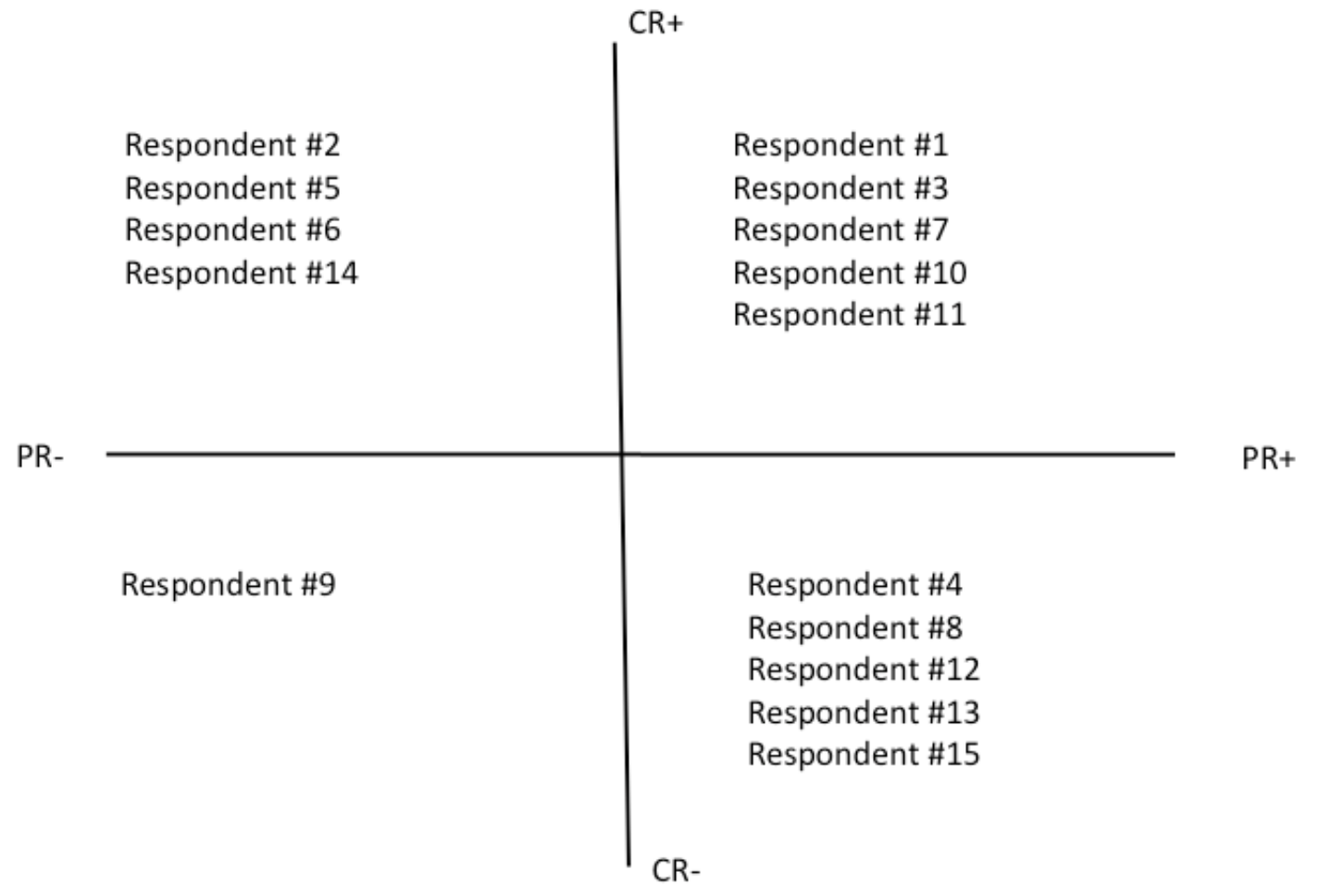

Following this initial allocation of participants, thematic analysis was subsequently employed to identify all germane perceptions or perspectives from the interview data in terms of the Baudrillardian domains described above (e.g. in terms of use, exchange and signifying values associated with evidence use). Specifically a hierarchy of thematic codes was developed to explain interview responses, with the development of codes occurring both inductively and deductively (Lincoln and Gubba, 1985): inductive analysis was first used to provide an initial categorisation of responses, and once all data 
was coded this way, mid level codes were built from the aggregation of these codes until all of the initial codes could be adequately explained in a conceptually meaningful way. These mid level codes were then organized within the higher level codes of use, exchange and signifying values (UES values). The resulting coding tree is set out in Figure 2 and the allocation of codes by quadrant is set out in Figure 3, below.

Figure 2: The hierarchy of thematic codes

Use

Recognizes the benefits of using research

Recognizes school or federation support for EIP

Enquiry mindset:

- reflection on academic research

- felt able to experiment

- how to experiment confidence

Collaborative orientation:

- learning conversations

Network orientation:

- networked learning conversations

- knew who to turn to for support

- Knew where to go to access research

\section{Exchange}

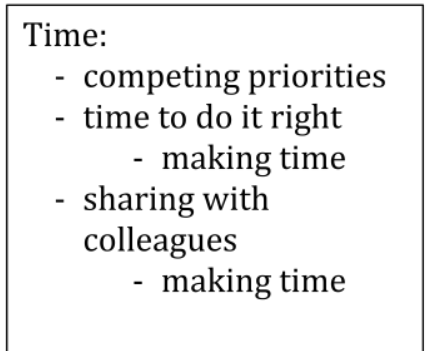

Financial cost

Access
Signifying

Reflective, empowered teachers who constantly improve their practice

Confidence to collaborate

Providing a route to better practice

Useful tool which provides a route to better student outcomes

Confident professional autonomy

Performativity and accountability

Figure 3: Allocation of thematic codes according to respondent's practical and cultural rational beliefs 
Following coding, a comparison was then made between the codes sitting under each UES value domain within in each quadrant. This was done in order to ascertain whether there were any meaningful differences in respondents' semiotic perspectives vis-à-vis their differing cultural and practical rational beliefs

\section{Findings from the interview data}

The findings for each quadrant are now explored in full, with findings organized, first by UES value, and then by their mid-level and initial codes, thus providing a comprehensive description of the perspectives of respondents in relation to their practical and cultural rational perspectives. The analysis begins with the optimal rational position represented by the $\mathrm{CR}+\mathrm{PR}+$ quadrant. 


\section{Findings for the CR+/PR+ quadrant}

Beginning with the Baudrillardian value of 'use', five mid level and nine initial codes were identified within the $\mathrm{CR}+/ \mathrm{PR}+$ quadrant. The first of these mid level codes was recognizes the benefits of using research, which highlights respondents' beliefs that the regular use of research to inform practice would result in better outcomes for children. For instance, respondents noted that the focus of EIP needed to be about improving children's outcomes '[when you know] things could be better or more effective' (respondent \#3).

Participants in this quadrant could also readily identify leadership support directed at encouraging EIP (mid-level code: recognizes school/federation level of support for EIP). For example that senior leaders with the federation were scheduling the school timetable to allow collaboration: '[name of senior leader] makes it work because he timetables meetings [so that we can all attend]' (respondent \#11).

Responses within the $\mathrm{CR}+/ \mathrm{PR}+$ quadrant also highlighted the enquiry mindset of participants, which was demonstrated in three specific ways. First was a reflection on academic research by respondents: this code often reflected the responses of those who had relatively recently completed an undergraduate degree, Masters degree or even $\mathrm{PhD}$, typically alongside their teaching role. As a result of being in a situation which required them to actively combine study with work, these respondents had developed a mindset of continuously reflecting on how the research they were engaging with might support their teaching practice: 'I do try to use that [the research] to inform practice at all 
times. I often find in my head l'm thinking "How does this impact the children, or my own learning?"' (respondent \#1); 'I start thinking about how I could develop that with the children' (respondent \#10).

The enquiry mindset of participants was also highlighted by responses which showed they felt able to experiment and that they knew how to experiment, thus maximizing the use value they might get from research. Beginning with the first of these, it was apparent that participants understood the benefits of experimentation and an acceptance of the risks involved in doing so. For instance, one noted: 'it can be difficult sometimes, but I think you've got to be open to trying something new. So... if you read something and you think "Oh I wouldn't mind having a go" it could go completely wrong. And its having the confidence to accept that' (respondent \#1). Knowing how to experiment effectively was also a key feature of the responses of this group. For example respondents understood the need to try to iteratively refine approaches to maximize their effectiveness. As one noted: 'how often do we need to do [interventions] and how smartly can we do them so they have the most impact?' (respondent \#7).

Participants more generally discussed the importance of having an collaborative orientation as a way of informing practice. For example one respondent noted the importance of learning conversations as a way of assessing whether and how new practices should be adopted, noting that as part of these there are a number of key considerations: 'if we are discussing something we may want to introduce, we often then say "well what's the 
purpose?"..."How will this impact? How will we know?"' (respondent \#1). One perceived benefit of engaging in learning conversations was that they challenged complacency and the formation of poor habits (i.e. doing things simply because they had 'always been done that way': respondent \#3). Learning conversations also enabled participants to engage in new ideas: '[otherwise] there is the danger that you don't remain current and abreast of everything' (respondent \#10). Learning conversations were universally seen as being strengthened by research - again leading to an increased perception of the use value of research.

Networked learning conversations that involved participants from across all three schools were also viewed as positive (as well as reflecting participants' network orientation: Daly, 2010). As one respondent noted: 'so an organization like this, part of the strength is that we can learn from each other, we know its powerful when we do it' (respondent \#7). Practice and research sharing formed a prominent aspect of these conversations and participants also displayed a network orientation in that they knew who to turn to for support: i.e. that they were able to identify who within the federation might support them with engaging in EIP if required. Also that respondents knew where to go to access research; i.e. they could identify who and where they might go to access research.

Moving to the Baudrillardian value of exchange, two mid level codes were identified, both of which related to the costs of EIP. The first of these was time, which was often regarded as a barrier to achieving even more (with the 
initial level coding reflecting the need to find time to do it right). Included here was the time needed to ensure sufficient good quality research could be drawn on: 'it takes time to find it' (respondent \#11). Sharing with colleagues or the brokerage of research or research informed strategies was also seen as key but time consuming, since it was recognized that sharing is only effective when research is 'effectively translated' (respondent \#11) ('you've got to know how to translate it': respondent \#10).

Finally, in terms of the signifying values of EIP, respondents suggested that, to them, EIP signaled the presence of reflective, empowered teachers who constantly improve their practice. At the same time, findings here also suggest that respondents viewed the use of research as something that would provide the confidence to collaborate with others across the federation: the use of research thus seen as providing a firm basis upon which to debate and engage in discussion around effective forms of teaching and learning. For instance, responses to the question "when I say research informed teaching, what image does that convey to you?" included: 'empowering, confidence and exciting' (respondent \#1); 'knowledge, relevancy and informing' (respondent \#10); 'an evidence-informed teacher is someone that has the confidence to open themselves up to being challenged' (respondent \#1); 'a reflective teacher. A teacher that's really challenged themselves to improve' (respondent \#11); 'its having the confidence to change things, and to look at things and to take that [research] onboard and to change the way you are working' (respondent \#13).' 


\section{Findings for the CR+/PR- quadrant}

Moving now to the $\mathrm{CR}+/ \mathrm{PR}$ - quadrant and beginning again with the Baudrillardian value of 'use', four mid level and initial codes were identified. The first of these was recognizes school/federation level of support for EIP. Here responses suggested, for example that: 'over the last year its been more highlighted [as something we should do]... and the language of using research-based evidence to inform your practice... its become more of our vocabulary' (respondent \#14); likewise: 'it's a culture that's become sort of recognized as 'this is the way that we should be working all the time, that we can work like this... we can be creative about things' (respondent \#14). Responses also indicated an enquiry mindset since participants also felt able to experiment: 'its very trial and error... but yes I feel l've got that freedom to experiment a little bit (respondent \#5). This type of mindset thus likely to make teachers more open to using research as part of a process of experimentation.

As with the $\mathrm{CR}+/ \mathrm{PR}+$ quadrant above, learning conversations (reflecting participant's collaborative orientation) were often used and seen as a beneficial way of challenging entrenched practice that might not always be effective: "they stops us doing things... because you've always done it (respondent \#2); ‘[we ask] if its not working then why isn't it working? [is] there another way of doing things?' (respondent \#14). As before, learning conversations were seen as being strengthened by research but, for these participants, this was less well established: 'we've talked about [research] a little bit, like five minutes at a speed dating style staff meeting... they're 
becoming more knowing that [practice] has to be backed up by [research]' (respondent \#2).

Respondents in this quadrant also actively connected with colleagues in other schools in order to collaborate and learn from each other through networked learning conversations (again reflecting their network orientation). While this collaboration involved sharing it also involved the hallmarks of effective brokerage (e.g. Rogers, 2003), where underpinning principles were discussed with questions asked such as 'how did you do that' or 'what [exactly] did you use that for' (respondent \#5), there was also practical application: 'we've tried lots of ways of doing things' (respondent \#14). Moving forward it was also hoped that this collaboration would increase and also extend to EIP.

Four mid level codes were identified for exchange, of these three were related to the time costs associated with engaging in EIP. For this quadrant, such costs were associated with the time [needed] to do it right: i.e. engaging with research effectively and meaningfully. More specifically, this time cost included: 'time to find out about the research, time to find out how to implement it and the time that it's going to take to do it differently when you're very busy... [for a new research-informed approach or piece of evidence] its going to take me time to read up on it, it's going to take me time to translate that into practical classroom activities and its going to take me time to do it differently for a while until it becomes an integral part of my practice (respondent \#2). 
What's more the cost of time also stretched to sharing with colleagues: ensuring that colleagues, such as teaching assistants (TA), understood how to use the approach as well. In both cases there was an anxiety about finding this time (making time), but it was felt that such issues would be manageable if protected time was allocated: '[ideally someone would say] this is your research time, go and do that. Don't think about planning. Don't think about class. You've got an afternoon to solely focus on your research'. (respondent \#6). One final exchange value code was the cost of access. Here some expressed a worry as to whether they might understand formal academic research: 'I guess sometimes, thinking back to research and papers, it's the jargon that's used [sometimes you] read and think "what was that about?" (respondent \#6).

In terms of the signifying values, it was clear that respondents in this quadrant associated EIP with the qualities of the enquiry mindset expressed by others those already engaged in research-use (i.e. those in quadrants $\mathrm{CR}+/ \mathrm{PR}+$ and $\mathrm{CR}-(\mathrm{PR}+)$, with that mindset then providing a route to better practice. More specifically, EIP was associated with teachers who reflect using research and develop deeper pedagogic knowledge as a result; who are willing to try new approaches; and who experiment to take risks to improve practice. What's more research-use was also seen to providing confidence to collaborate and a secure basis for evidence informed teachers to be both collaborative and network orientated. This is nicely expressed in the following quote: '[a evidence informed teacher is] somebody who is confident in what they are 
doing, confident in their job, knows best practice, willing to try new things' (respondent \#6).

\section{Findings for the CR-/PR+ quadrant}

Within the CR-/PR+ quadrant there were five use codes, one exchange code and one signifying code. On contrast to the first two quadrants, however, two of the use codes indicated negative perspectives and a further use code represented a localized focus. The first of the positive codes was recognizes the benefits of using research. In other words, it was thought by respondents in this quadrant that using research could result in better practice. This is nicely reflected in the response of following interviewee who stated that: 'I need [to use research] to address problems in my classroom, to inform me about what I'm going to do and to gain' (respondent \#4). Others noted that because they had just taught a difficult cohort of children, they had turned to research to provide them with specific pedagogic strategies. Overall, however, the responses of those allocated to this quadrant tended to reflect a more reactive rather than continuous engagement with research: 'it [engagement with research] is mainly a reaction to things that are happening in the classroom, not something that's been ongoing' (respondent \#13).

It was also apparent that respondents within this quadrant exhibited an enquiry mindset. This was indicated first by participants' reflection on academic research. Here, as before, this code often applied to the responses of those who had relatively recently completed a degree, or post graduate qualification: 'I think partly because I have studied recently [that enquiry 
mindset] is fresh and I enjoy research' (respondent \#4). What's more responses also indicated that they felt able to experiment: 'you can run with stuff and if it works and it gets results [the headteacher] is happy to go with it... I feel l've got a huge amount of freedom [to innovate]' (respondent \#4).

In terms of the negative codes, it was clear that participants in this quadrant could not point to examples of leadership support directed at encouraging EIP more widely (recognizes school/federation level of support for EIP). They could however suggest what support was required if EIP was to materialize at a school or federation level: "[there needs to be] a lot of communication and... clarity on what staff are going to do and what they need to go away and do... really clear objectives... and allocated time provided' (respondent \#15).

The code indicating a localized research-use focus was that of purpose, which represented the tension felt by respondents when attempting to meet the micro and macro level demands they regularly faced. Specifically, participants noted that the focus of the research-use activity needed a recognizable purpose if they were to buy into it. Sometimes this meant that they felt the focus for EIP should be at the level of the classroom rather than the level of the federation: 'I think people have to see the purpose of it... [in the past] I found it difficult to buy into because I didn't agree on what it was... and I didn't really understand why it was...It has to be something that people believe is worthwhile [whereas in the past] what we actually felt we needed was to make ourselves better prepared [for meeting local needs]' (respondent \#4); '[it needs to be] something which is directly important to us and our school' 
(respondent \#12). In part, as is shown below, this may be because of the difficulties faced at the local level (for example some respondents referred to a difficult cohort they had just finished teaching); also the competing priorities that can manifest locally, meaning that any new activity has to be regarded as $100 \%$ meaningful, if it is to carry weight.

What's more, the network orientation of participants indicated a lack of depth of engagement with others. While those in the $\mathrm{CR}+\mathrm{PR}+$ and $\mathrm{CR}+/ \mathrm{PR}$ quadrants employed networked learning conversations, those in this quadrant were more likely to engage in more superficial collaboration with networked peers (e.g. Warren Little, 1982). For example, the simple sharing (i.e. exchange) of resource, rather than deep engagement with peers that centres on how to use the resource effectively: 'networking [extends to sharing] and using the resources of other schools' (respondent \#4); 'being part of a federation, you are sharing expertise, aren't you? Something that [other teacher] does at [other school] and works really well, we can all try' (respondent \#13). Likewise, any form of networked collaboration was seen at the level of 'email[ing] each other and keep[ing] in contact' (respondent \#13). Occasionally there was active rejection of a networked approach: 'I hope we do it in school, its more of an issue to work across the federation' (respondent \#8).

Finally a key issue for those in this quadrant was the number of competing priorities that often seemed to 'get in the way' of research-use (the exchange vale of time). As one respondents noted: 'last year in school we had 
OFSTED... I was moderated, we had difficult relations with some parents and children... I think there has to be space otherwise you can't do it' (respondent \#4); 'We haven't time to sit down and talk to each other and communicate with each other... school is so full-on and so busy' (respondent \#15). This led to others noting that their research activity tends to happen 'in our own time' (respondent \#6). As highlighted above, the feeling that there were competing priorities, and a lack of time - along with a lack of recognition of any supporting structures or culture for research-use at the school/federation level, reinforced the use of research to tackle only local and immediate classroom level priorities.

With these factor combined, it is perhaps no surprise that when it came to the signifying values associated with research-use, respondents within this quadrant tended to articulate a practical purpose. For instance, evidence use was regarded as a useful tool which provides a route to better student outcomes. As one respondent noted, the purpose of EIP is: 'having something that you maybe want to address or something that you want to move forward and saying "how can I have a better understanding? How can I make this better or improve this?"' (respondent \#4). A research-informed teacher meanwhile was seen as having good pedagogic knowledge (respondent \#4): research-use thus seen as providing the basis for confident professional autonomy. In keeping with the analysis above, the imagery associated with EIP also had a local focus: 'its using evidence that other people have gathered in your own classroom in your own way' (respondent \#15). 


\section{Findings for the CR-/PR- quadrant}

Only one respondent provided responses to suggest that they held CR-/PRbeliefs. Because these responses were atypical in comparison to those held by other respondents and because only one individual held them, they will not be reported in detail for two reasons. The first is ethical and relates to the likelihood that this individual could be identified through the use of direct quotations. The second relates to the trustworthiness: it is not possible to triangulate the perspectives of this respondent with others who hold CR-/PRbeliefs (Lincoln and Guba, 1985). Nonetheless of interest, given that it is possible to triangulate these codes to the analysis above, is that in terms of use value, unlike with other quadrants, this participant did not feel able to experiment (they thus demonstrated a negative enquiry mindset). In terms of exchange value, this respondent also flagged the issue of competing priorities. Finally while respondents located in the other three quadrants universally linked EIP to solving problems, developing an enquiry habit of mind (OECD, 2016), becoming a reflective practitioner and developing $21^{\text {st }}$ century learners, this respondent linked EIP directly to performativity and accountability.

\section{Discussion}

Overall, a summary of the main findings indicates that:

1) $\mathbf{C R}+/ \mathbf{P R}+$ teachers had a firm understanding of the benefits of employing research, felt it provided an exciting vision for the future and felt that senior leaders (both at school and federation level) were encouraging them to experiment using research-informed approaches to realize these benefits/this 
vision. Teachers in this quadrant believed in the importance of collaboration and in maximizing the benefits of being in a network and because of this, viewed EIP as having a use value that went beyond the individual classroom: i.e. that it should involve collective endeavor in order to harness the benefits of the social capital potentially available to them. At the same time, researchuse was regarded as providing a secure knowledge base upon which to engage in collaborative networked activity,

2) $\mathbf{C R}+$ /PR- teachers recognized that senior leaders were encouraging them to use research-informed approaches and were happy to consider engaging in EIP, since this both represented a natural extension of and supported existing collaborative activity such as networked learning conversations. They also saw EIP as helping them fully develop an enquiry habit of mind. Although these teachers were yet to fully understand the practical benefits of EIP, they were cognizant of the costs required to engage in it effectively.

3) CR-/PR+ teachers, perhaps because of time pressures, held different views. While they understood the benefits of employing research, they considered EIP primarily as a 'tool': something relevant to tackling local (classroom level) issues, rather than something to be used collaboratively to tackle the strategic and more distant goals of the network. As a consequence, teachers in this quadrant were more likely to use research solely to develop their professional autonomy: to try out new strategies and build up a repertoire of research-informed pedagogies that focused solely on day to day student issues. 
As well as examining findings across individual quadrants, it is also possible to undertake a 'cross case' approach to examine what informs the practical and cultural rational beliefs that form the basis of the quadrant axes. Beginning with $\mathbf{P R +}$, and examining data from both $\mathrm{CR}+\mathrm{PR}+$ and $\mathrm{CR} / \mathrm{PR}+$ quadrants, it would seem that key to driving participant's practical rational beliefs is their first hand understanding of the benefits. For instance, those participants who recognize[d] the benefits of using research, were those who had already been actively engaging in EIP (irrespective of their $\mathrm{CR}+$ position) and often had recent formal experience of reflection on academic research, possibly via postgraduate study. Conversely, teachers in the CR+/PRquadrant did not make explicit mention of the benefits of EIP but recognized existing support for it and possessed the type of enquiry mindset (felt able to experiment) that, in the other quadrants, appeared to underpin effective of research-use.

CR+: As can be seen from questions 3) and 4) in table 1, a key aspect of the cultural rational position for EIP is that it represents a community wide endeavor: in this respect EIP represents an ethos rather than an activity, since it involves schools engaging with research to focus on strategic as well as local priorities (Stoll et al., 2006). It would seem therefore that a fundamental part of what drives agreement with the $\mathrm{CR}+$ proposition is the extent to which research-use is perceived as being something that should extend beyond the local setting: in other words $\mathrm{CR}+$ EIP relates to both respondents' collaborative and networked orientations (e.g. their use of 
learning conversations and networked learning conversations) and the extent to which evidence-use signifies not just a tool, but something that leads to $21^{\text {st }}$ century teaching and learning within what the OECD refers to as "learning organisations' (OECD, 2016). Simultaneously, research-use was also seen by participants situated within the CR+ quadrants as supporting collaborative networked activity. This is because it was regarded as providing a secure knowledge base, so enabling teachers to feel more confident in engaging in debates about effective teaching and learning.

Related is the recognition from teachers holding $\mathrm{CR}+$ beliefs, that senior leaders within the federation are encouraging of the EIP agenda (recognizes school/federation level of support for EIP) and, vitally, also engaging in acts (such as timetabling) to enable networked collaboration. Where participants were CR- they not only perceived that EIP should not extend beyond their classroom, they also engaged in more superficial collaboration (Warren Little, 1982) and highlighted a lack of support to encourage them to engage in research-use (most often citing competing priorities as the reason that EIP was only likely to materialize locally).

Situating these findings within the wider theoretical field, it is clear that they both cohere with and augment other work in the areas of research-use and educational change at the system level. They also provide vital insights if Chestnut Learning Federation is to achieve its improvement plan objectives to become an evidence-informed Federation by shifting the perspectives of its teachers towards the $\mathrm{CR}+/ \mathrm{PR}+$ quadrant. To begin with, the findings reaffirm 
the vital importance of first-hand experience if individuals are to buy-in to new ways of working, such as that represented by using research evidence (e.g. Fullan, 2011). Also, that teachers need to feel able to experiment if they are to fully engage in EIP type activity (e.g. Katz et al., 2009; Roberts, 2015). Key to increasing PR+ perspectives amongst teachers in Chestnut Learning Federation therefore is that the Federation ensures teachers are able to engage with and apply research when attempting to improve their practice and that they can recognise the impact of doing so.

These findings also reaffirm that senior leader support is key to fostering a culture of research-use. As Earl and Katz (2006: 20) argue, 'leaders have the challenge of convincing everyone who works in a school of the merits of using [evidence] for productive change and creating the conditions in which [evidence] can become an integral part of school decision making'. Such conditions include coordinated and protected time and space, as well as access to relevant research resource (Galdin O'Shea, 2015). Senior leadership support is also essential for networked activity to take root and flourish (Rinćon-Gallardo and Fullan, 2016). Support in these areas is most effectively delivered via a mixture of transformational leadership strategies as well as school leaders 'walking the talk': showcasing the research-related behaviours expected of staff (Stoll, 2015). In particular, however, the findings from this study highlight the requirement for Chestnut Learning Federation to promote the idea of community while also ensuring staff are both encouraged and supported (and it is modeled to staff how) to engage in research-use in a networked way. Here all staff must move beyond the superficial exchange of 
practices and resource and towards meaningful research-related collaboration that has demonstrable benefits for both individual teachers and the Federation as a whole. Indeed, we believe it is the use of networks in ways that produce a multitude of benefits at a variety of levels that is likely to be key to unlocking the potential that the optimal rational position of EIP has to offer.

\section{References}

Ball, S. (2008) The education debate, (Bristol, The Policy Press).

Ball, S. (2012) Global Education Inc. New Policy Networks and the NeoLiberal Imaginary (Abingdon, Routledge).

Baudrillard, J. (1968) The System of Objects, (London, Verso).

Bryk, A., Gomez, L. and Grunow, A. (2011). Getting ideas into action: Building Networked Improvement Communities in Education, in Hallinan, M. (ed) Frontiers in Sociology of Education (Dordrecht, NL, Springer).

Cain, T. (2015) Teachers' engagement with published research: addressing the knowledge problem, Curriculum Journal, 26, 3, pp. 488-509

Caldwell, M., Greany, T., Higgins, S., Maxwell, B. Stiell, B., Stoll, L. Willis, B. (2015) Evaluation of progress towards an evidence based teaching system, including DfE's role in facilitating progress. INTERIM REPORT AUGUST 2015. 
Cooper, A., Levin, B. and Campbell, C. (2009) The growing (but still limited) importance of evidence in education policy and practice, Journal of Educational Change, 10, 2-3, pp. 159-171.

Cordingley, P. (2008) Research and evidence-informed practice: focusing on practice and practitioners, Cambridge Journal of Education, 38, 1, pp. 37-52

Dagenais, S., Mayer, J., Wooley, J. and Haldeman, S. (2008) Evidenceinformed management of chronic low back pain with medicine-assisted manipulation, The Spine Journal, 8, 1, pp. 142-149.

Daly, A. (2010). Mapping the terrain: Social network theory and educational change, in Daly, A. (Ed), Social Network Theory and Educational Change (pp. 1-16), (Cambridge, MA: Harvard Education Press).

Earl, L. and Katz, S. (2006) Leading schools in a data rich world (Thousand Oaks, CA, Corwin Press).

Eco, U. (1967) Travels in hyperreality, (London, Picador).

Eco, U. (1979) A theory of semiotics, (Bloomington IN, Indianna University Press). 
EEF (2014) EEF launches £1.5 million fund to improve use of research in schools, available at: https://educationendowmentfoundation.org.uk/news/eeflaunches-15-million-fund-to-improve-use-of-research-in-schools/, accessed on 27 September, 2015.

Fairclough, N. (1995) Critical Discourse Analysis: The critical Study of Language, (Harrow, Longman).

Fullan, M. (2011) Change leader: Learning to do what matters most, (San Francisco, Jossey-Bass/Wiley).

Galdin-O'Shea, H. (2015) [citation removed for peer review]

Gibbons, M., Limoges, C., Nowotny, H., Schwartzman, S., Scott, P. and Trow, M. (1994) The New Production of Knowledge: The Dynamics of Science and Research in Contemporary Societies, (London, Sage).

Goldacre, B. (2013) Building Evidence into Education, (London, Department for Education, available at: www.gov.uk/government/news/building-evidenceinto-education, accessed on 9 August 2016.

Gough, D., Tripney, J., Kenny, C., Buk-Berge, E. (2011) Evidence informed policymaking in education in Europe: EIPPEE final project report summary, available at: 
www.eipee.eu/LinkClick.aspx?fileticket=W6vkqDjbil\%3d\&tabid=2510\&langua ge=en-GB, accessed on 11 September 2012.

Green, S. (2002) Rational Choice Theory: An overview, (Waco, TX, Baylor University).

Hammersley-Fletcher, L. \& Lewin, C. (2015). Evidence-based teaching: Advancing capability and capacity for enquiry in schools. Interim report. (Nottingham, National College for School Leadership).

Hattie, J. (2011). Visible Learning: A Synthesis of over 800 Meta analyses Relating to Achievement, (Abingdon, Routledge).

Katz, S., Dack, L. A., and Earl., L. (2009) Networked Learning Communities: Fostering Learning for Teachers and the Students. Principal Connections, 12, 3, pp. 36-38.

Lincoln, Y., and Guba, E. (1985) Naturalistic Inquiry, (Newbury Park, CA, Sage Publications).

Mincu, M. (2014). Inquiry paper 6: teacher quality and school improvement what is the role of research? In the British Educational Research Association/ The Royal Society for the encouragement of Arts, Manufactures and Commerce (Eds), The Role Of Research In Teacher Education: Reviewing 
The Evidence, retrieved from https://www.bera.ac.uk/wpcontent/uploads/2014/02/BERA-RSA-Interim-Report.pdf, accessed on November $8^{\text {th }} 2015$.

Nelson, J., Mehta, P., Sharples, J. and Davey, C. (2015) Measuring teachers' research engagement: Findings from a pilot study (London, Education Endowment Foundation and National Foundation for Educational Research).

Nelson, J. and O'Beirne, C. (2014) Using Evidence in the Classroom: What Works and Why? (Slough, National Foundation for Educational Research).

OECD (2016) What makes a school a learning organization, available at: http://www.oecd.org/education/school/school-learning-organisation.pdf, accessed on 25 July, 2016.

Oxman, A., Lavis, J., Lewin, S., and Fretheim, A. (2009a) SUPPORT Tools for evidence-informed health Policymaking (STP) 1: What is evidence-informed policymaking?, available at: www.health-policy-systems.com/content/7/S1/S1, accessed on 14 November 2015.

Peirce, C. S. (1960) Collected Papers of Charles Sanders Peirce, Volumes V and VI, (Cambridge: Harvard University Press). 
Rinćon-Gallardo, S. and Fullan, M. (2016) Essential features of effective networks in education, Journal of Professional Capital and Community, 1, pp. $5-22$.

Roberts, C. (2015) [citation removed for peer review].

Rogers, E. (2003) Diffusion of innovations (5 ${ }^{\text {th }}$ Edition) (New York, NY, Free Press)

Sen, A. (1990) Rational Behaviour, in Eatwell, J., Milgate, M. and Newman, P. (eds) Utility and probability (pp. 198-216) (New York, NY, W. W. Norton).

Shavelson, R. J., and Towne, L. (Eds.) (2002) Scientific research in education, (Washington, DC, National Academy Press).

Stoll, L. (2015) Three greats for a self-improving school system: pedagogy, professional development and leadership: executive summary, available at: https://www.gov.uk/government/uploads/system/uploads/attachment_data/file/ 406279/Three_greats_for_a_self_improving_system_pedagogy_professional_ development_and_leadership_executive_summary.pdf, accessed on 27 February, 2015.

Stoll, L., Bolam, R., McMahon, A., Wallace, M. and Thomas, S. (2006) Professional learning communities: a review of the literature, Journal of Educational Change, 7, 4, pp. 221-258. 
Supovitz, J. (2015) [citation removed for peer review]

Tan, E. (2014) Human Capital Theory: A Holistic Criticism, Review of Educational Research, 84, 3, pp. 411-445.

Warren Little, J. (1982) Norms of Collegiality and Experimentation: Workplace Conditions of School Success, American Educational Research Journal, 19, 3, pp. $325-340$.

\footnotetext{
i See: http://www.teachmeethants.co.uk/sample-page/

ii See: http://www.workingoutwhatworks.com
} 